\title{
Assessment of Subgrade Degradation Induced Mud Pumping at Railway Track: A Review
}

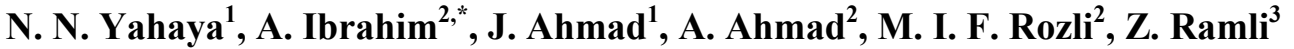 \\ ${ }^{1}$ School of Civil Engineering, College of Engineering, Universiti Teknologi MARA, 40450 Shah Alam, Selangor, Malaysia \\ ${ }^{2}$ School of Civil Engineering, College of Engineering, Universiti Teknologi MARA Cawangan Pulau Pinang, Kampus Permatang Pauh, \\ 13500 Permatang Pauh, Pulau Pinang, Malaysia \\ ${ }^{3}$ Keretapi Tanah Melayu Berhad, Pejabat Jurutera Wilayah Utara, 14000 Bukit Mertajam, Pulau Pinang, Malaysia
}

Received May 20, 2021; Revised October 19, 2021; Accepted November 30, 2021

\section{Cite This Paper in the following Citation Styles}

(a): [1] N. N. Yahaya, A. Ibrahim, J. Ahmad, A. Ahmad, M. I. F. Rozli, Z. Ramli, "Assessment of Subgrade Degradation Induced Mud Pumping at Railway Track: A Review," Civil Engineering and Architecture, Vol. 10, No. 1, pp. 345-355, 2022. DOI: 10.13189/cea.2022.100129.

(b): N. N. Yahaya, A. Ibrahim, J. Ahmad, A. Ahmad, M. I. F. Rozli, Z. Ramli (2022). Assessment of Subgrade Degradation Induced Mud Pumping at Railway Track: A Review. Civil Engineering and Architecture, 10(1), 345-355. DOI: $10.13189 /$ cea.2022.100129.

Copyright $(2022$ by authors, all rights reserved. Authors agree that this article remains permanently open access under the terms of the Creative Commons Attribution License 4.0 International License

\begin{abstract}
Generation of mud pumping is commonly triggered by a combination of three main factors such as excess fines, excess water, and cyclic loading. Excess fines particle is generated from depositing mechanisms (i.e., dust, waste material and ballast breakage) and fluidisation or internal erosion mechanism (i.e., subgrade degradation). Mud pumping phenomenon that is associated with ballast fouling has been widely discussed and is of interest among the railway engineers and researchers. However, subgrade degradation or fluidisation of subgrade layer induced mud pumping mechanism gained less attention from the researchers due to complexity of subgrade soil behavior. Various methods applicable in railway track's subgrade degradation assessment based on destructive and nondestructive test were comprehensively reviewed in this research paper. The assessment on subgrade mud pumping is based on migration of the subgrade fine mechanism including in-situ excavation test, particle size distribution test, ground penetrating radar (GPR) and physical modelling test. This paper summarizes the advantages and weaknesses of various assessment methods of subgrade degradation induced mud pumping and clarifies most effective method for repair and maintenance of railway track.
\end{abstract}

Keywords Mud Pumping Mechanism, Rail Tracks, Assessment, Fluidisation, Subgrade Degradation

\section{Introduction}

The mechanism of mud pumping is a complex process, and real-time assessment of mud pumping must be carried on site to understand the loading and basic characteristics of ballasted railway track. The conventional mitigation approach for mud pumping problems is to directly modify or replace the fouled section of rail tracks to improve the drainage system and bearing capacity. However, this repeated localised maintenance work is usually expensive as it does not completely solve the mud pumping problem $[1,2,3]$. Identifying the appropriate mechanism of mud pumping has the potential to reduce maintenance cost by utilizing the cost-effective remediation work.

Nguyen et al. [4] pointed out three major sources of excess fines include (a) degradation and infiltration of filter and subgrade layers, (b) ballast breakage and (c) external fines as illustrated in Fig. 1. When referring to the flow/mode of pumping fines, sources (a) is required/possessing complex process due to the development of excess pore water pressure during loading impact as resulting fluidization to take place in subgrade soil. Different with simpler mechanism, other sources only involving with fine accumulate due to ballast breakage and abrasion impact (sources b) and subsurface infiltration of transported dust and coal (sources c).

Source (a) is induced mainly by subgrade fines migrating from subgrade layer which infiltrates into 
ballast layer. Many studies $[3,5,6]$ show prevalent content of silt and sandy grains whereas some investigations $[7,8]$ report that mud pumping could occur with clayey soils. According to Chawla and Chawla et al. [9] the mud pumping is possible to occur when the track laid on typical silty soil type, due to high permeability which fastened the fine particle to rise and low plasticity causing easier path for displacement of fine particle through pore water development. Meanwhile, for coarse grained soil is not effective on mud pumping formation due to small height capillary rise and unable to maintain at certain saturated state unless it consists of silt and clay content which causes the increment of frost heaving led to mud pumping creation [10].

Different from subgrade fines, the fine sources induced by ballast breakage (sources b) are merely unavoidable. As many studies $[11,12,13]$ show that fines are mainly developed by ballast breakdown rather than other sources. From site investigation conducted by Selig and Waters [11] discovered on $76 \%$ contribution of fine sources is from ballast breakage or ballast aggregate deterioration which takes place during heavy freight load and high-speed train surpass the track same goes with ballast tamping during maintenance works [11,14,15]. In 84 field sample of fouled ballast, Ionescu [16] had found only 5\% fine particles were induced by the subgrade fine. Thus, it is obviously showing most of the fouled ballasts were induced by ballast breakage.

The external sources are produced from external parts of rail foundation which are different from previous sources that are induced by the internal track foundation. According to Nguyen [4] the external substances commonly consist of coal, waste generated during freight train operation, dust accumulation transported by wind and/or rain and superstructure degradation. Ballast fouled from a coal dust normally generates in the country that involved with rapid development in coal industry which uses railway as dependable transportation [17]. The ballast contaminant near the derailed trackline of Unica, Nebraska, US had exceeded almost $14 \%$ finer than $0.075 \mathrm{~mm}$ which is much larger than the allowable percentage which is $1.5 \%$ in fresh ballast thus showing how much the contribution of coal contaminant in the fouled area is [4]. Meanwhile Feldman and Nissen [12] reported on coal dust accounts achieved for $70-95 \%$ of the ballast contaminant for coal freight tracks in Australia. Other than sleeper wear, contamination frequently produced from train such leaking fuel tank, grease dropping and heavy metals Johan [18] which possibly occur due to rapid contact between wheel and rail or wheel and brake pad when braking [19].

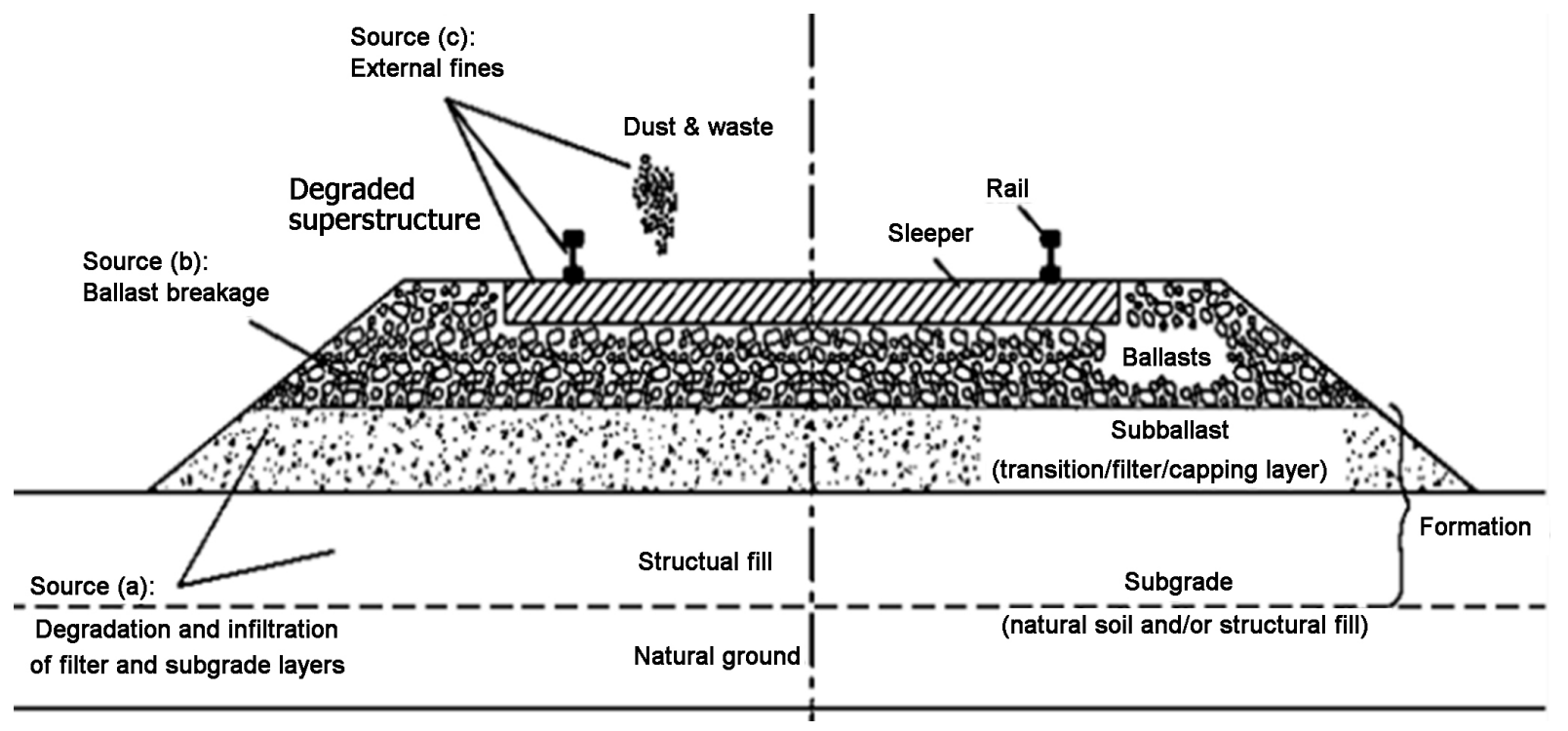

Figure 1. The sources of mud pumping generation [4] 


\section{Subgrade Degradation Prone to Mud Pumping Occurrence}

In late 1950s, the researcher began to investigate the pumping of subgrade soils in pavement engineering context whereas; since 1980s the researcher began having interest in mud pumping in railway engineering context [20]. Generally, mud pumping can be classified into two categories such as subgrade and ballast mud pumping [4]. Subgrade mud pumping mainly involves the migration of fine soft subgrade particles into the coarser layer [21] while ballast mud pumping is the dust or other fine substances accumulate inside the ballast aggregate [4]. There are three elements that trigger the subgrade degradation such as soil plasticity, water, and dynamic loads. Soil and water can be classified as internal parameter while the dynamic train loading is the external factor in forming the subgrade mud pumping. The beginning of development of mud pumping process is due to the existing soft saturated subgrade soil subjected to repetitive loading [21] and when the subsequent passage of trains over the wet spots, the cyclic loading led to the penetration of the ballast, which forced the fines to squeeze into the coarser upper layers and foul the void ballast.

Fig. 2 illustrates the phenomenon of mud pumping through the suction driven model proposed by Takatoshi [22]. It starts from the resilient sleeper deformation due to long term effect of train loading causing the development of void/space between sleeper-ballast or known as hanging sleeper [23] as referred to Figure 2(c). Apart from that, the tie-ballast gap development is partly the result of the initial loose or uncompacted ballast [24]. When the train surpasses the track, due to impact load, the ballast aggregate compacted and rearrange in solid state as pressed down thus dissipate high pore water pressure as illustrated in Figure 2(b). At unloading state as the sleeper restore to normal position, the suction force generates causing the migration of subgrade fine particle as display in Figure 2(a). The suction effect depends heavily on the ties-ballast distance as the gap increases, the pumping fine will actively move $[24,25]$. As pore water pressure development is the main influence on the dissipation of fine-grained particle of subgrade soil which causes the occurrence of mud pumping [26]. High intensity of water content in subgrade soil surface enables the rapid rate of pore water pressure diffusion provoked by suction force through loading and unloading process.

Basically, the mud pumping will appear only in moving train operation as under the repeated load, the subgrade soil will produce plastic deformation thus causing deformation and destruction for subgrade [27]. The major factor such as depth, speed train and loading influence the generation of excess pore water pressure in soil when under train loading $[28,29,30]$. Other than interpenetration between ballast and subgrade layer, the pore pressure is another contribution to mud pumping occurrence. The development of pore water pressure in the subsoil causing the migration of fine particle into ballast void as stated by Duong et al. [26]. Cyclic loading is the main reason of the increment of pore water pressure in railway formation which exaggerates the infiltration of subgrade fine through the surface layer as increasing the pore water pressure [4]. On the other hand, the presence of water supports the generation of pore-water pressure when under external loading thus allows the dissipation of this pressure to bring fine particles up to the ballast layer.

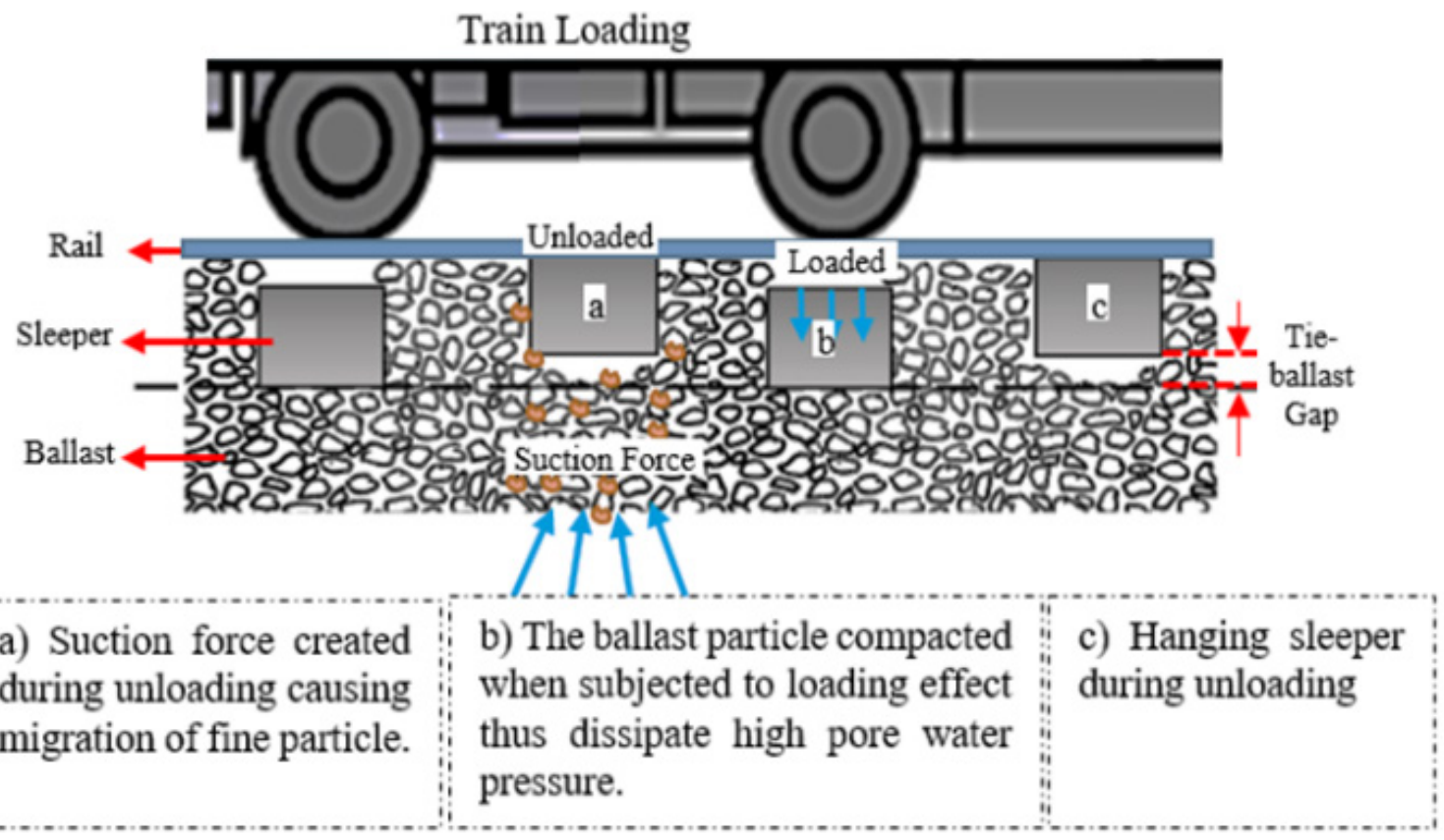

Figure 2. A schematic diagram of migration of fine particle grained through pumping effect. 
Furthermore, the drainage condition plays a key role in subgrade degradation induced mud pumping, it is obvious for mud pumping cannot occur without a certain condition of high-water table under the track. Numerous site investigations findings show that mud pumping occurs more frequently during high rainfall periods due to rising water tables and the increase in surface water concentration in the surface area [2,14]. Drainage issue can influence the instability and shear failure of the railway foundation $[13,23,31]$ as poor drainage tends to associate with water ponded/trap beneath the track which accelerate the degradation rate of structure. For example, Duong et al. [32] found that fines rise upwards more rapidly at a near saturated state with a high-water content (e.g., $>14 \%$ ), and this does not occur in unsaturated conditions. Although the role of water in the generation of mud pumping is evident, the mechanism at micro-scale, i.e., the particle-water interaction in this process has not been addressed very well.

However, further investigation is needed as the interaction of soil particle-water in the formation of mud pumping is not well addressed by previous researcher. Further step is required to establish the mathematical model which correlated to the dissipation of pore water pressure that causes the migration of fine particles on soil surface as highlighted by [25].

\section{Assessment on Subgrade Degradation Induced Mud Pumping}

The assessment of mud pumping can be carried out through a visual assessment [4] on the visible or invisible of mud pumping at the track surface. Visual inspection is a preliminary step before undergoing technical step such as field and/or lab testing and theoretical assessment [4].
Visible mud pumping is normally to be assessed as there is visible evidence such as fouled ballast or slurry mud on subsurface track [4]. Unlike slurry mud presence, it is more challenging to assess site without a sign of slurry mud pumping on the surface track $[33,34]$. The most frequent approach to identify the invisible mud pumping is conducting the visual inspection on track deformation particularly on track geometry and rail deflection. The degradation of track geometry can be verified through the distance between rails and track roughness [23,35]. Meanwhile the deflection-load profile of tie-ballast gap which represents the track stiffness can indicate the scene of degradation arise [36]. However, this method depends on weathering effect (wet or dry) which influences the track performance [13].

Fig. 3 shows the different assessment methods which study on subgrade mud pumping based on migration of the subgrade fine mechanism. Field (i.e., in-situ excavation test and geophysical method) and laboratory test (i.e., mud pumping modelling and analysis mud sample) are technical options for determining the occurrence of mud pumping from the subgrade layer. Only a limited number of experimental studies have been conducted to understand the pumping mechanisms of subgrade particles in pavement system $[37,38,39]$.

\subsection{Field Test}

Field test is critical for monitoring or investigating the actual trigger element that causes the formation of mud pumping. In-situ excavation and geophysical method is the appropriate method commonly used to identify the fine subgrade mechanism that occurs at bottom. Not all field tests are particularly appropriate to investigate the migration of subgrade fine to the bottom area.

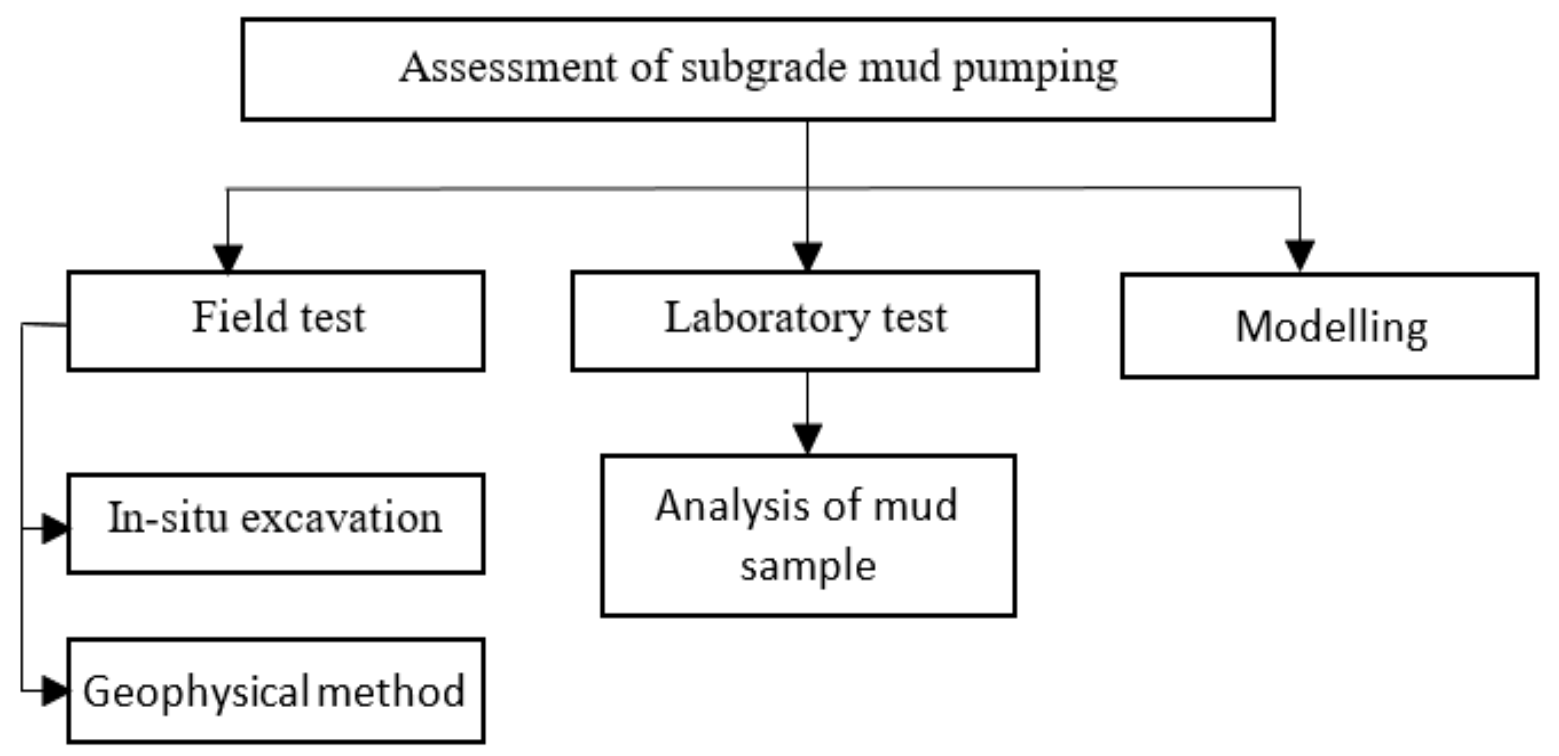

Figure 3. Typical assessment method of mud pumping (after [4]) 


\subsubsection{In-situ Excavation Test}

The in-situ excavation test can be used to visualize mud pumping directly on site. However, there is limited information that could be obtained from this method due to less effectiveness in the investigation of the mud pumping mechanism. This approach is reliable or appropriate to measure the mud pumping path and examine the conditions between the ballast and subgrade interface [40]. Kuo et al. [3] carried out an excavation test near the mud site to observe the distribution of mud pumping inside the ballast. Through the schematic diagram in Fig. 4 shows the normal concept of the distribution of mud pumping is not normally straight up but the pumped material can be compressed and flowed from any source or direction as they discovered almost filled of pumped materials beneath the clean ballast surface. Thus, the in-situ excavation directly on fouled ballast cannot guarantee that the main sources of unpredictable mud pumping flow identification unless further laboratory testing on mud.
Besides, this test is commonly used as a comparison assessment to achieve the exact/accurate data in site investigation. Kuo [41] conduct an excavation to make comparison with scanning image of GPR to ensure the accurateness in interpretation signal analysis on fouling ballast. The areas on the excavation map delineated as the mud pumping range provided the valid grid correctness rate to be calculated [41]. The comparison between the interpretation results and excavation results showing the overall accurateness was $82.1 \%$.

The in-situ excavation somehow was preferably avoidance due to high cost as the site disturbance among upper structure was getting involved thus causing interruption on railway operation otherwise the track is under major rehabilitation phase. However, the accuracy can be managed if investigation is started with geophysical method for assessing the mud flow path below/beneath the track. Excessive/extreme track settlement accused by critical mud pumping in poor subgrade soil required deep in-situ investigation to evade repetitive problem from happen/occur in future

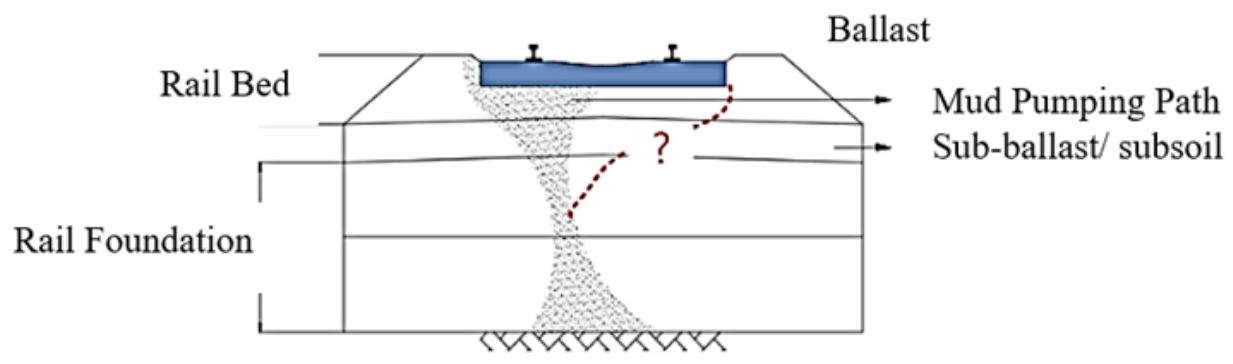

Figure 4. Schematic diagram for distribution of mud pumping using excavation test [3]

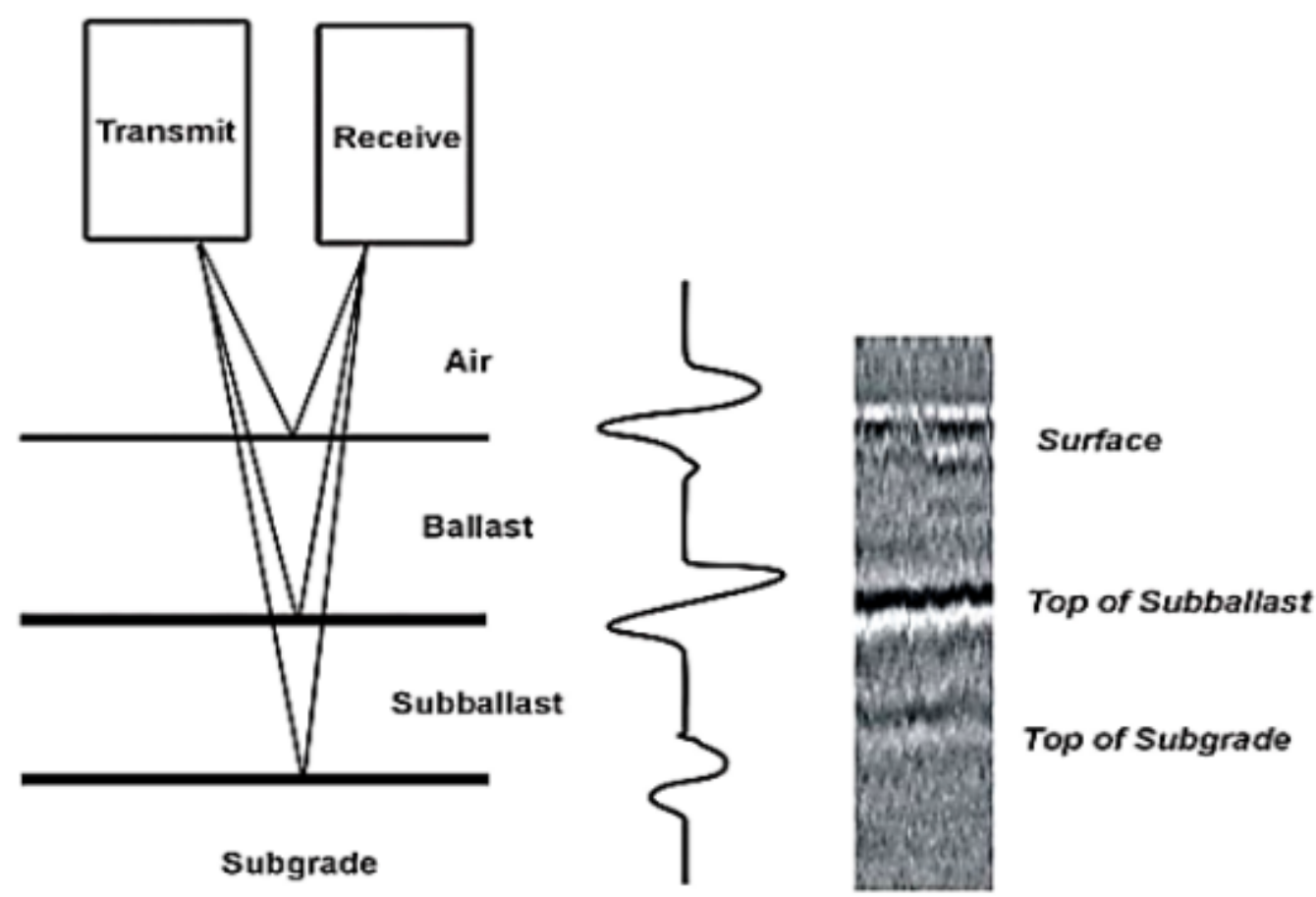

Figure 5. GPR profile diagram [42] 


\subsubsection{Geophysical Method}

Geophysical method is non-destructive method that can be used to identify the mud pumping from the subgrade particle based on the scanning the mud flow path until deep bottom area. This method is simple to use in practice as it is not disturbing the existing structure and capable to notify the drainage problems such as trapped or stagnant water in substructures. Ground Penetrating Radar, GPR is one of geophysical methods used for mapping underground. In railway track, GPR is generally used to inspect the quality of rail bed using radar pulse to image the subsurface and the reflected signal from each structure layer were detected via Electromagnetic radiat ion. Fig. 5 shows the GPR profile diagram of reflection signal response (left side of diagram) synchronizes with typical radar line (middle) and produces scan image at interface substructure [42].

\subsubsection{Geophysical Method}

Geophysical method is non-destructive method that can be used to identify the mud pumping from the subgrade particle based on the scanning the mud flow path until deep bottom area. This method is simple to use in practice as it is not disturbing the existing structure and capable to notify the drainage problems such as trapped or stagnant water in substructures. Ground Penetrating Radar, GPR is one of geophysical methods used for mapping underground. In railway track, GPR is generally used to inspect the quality of rail bed using radar pulse to image the subsurface and the reflected signal from each structure layer were detected via Electromagnetic radiat ion. Fig. 5 shows the GPR profile diagram of reflection signal response (left side of diagram) synchronizes with typical radar line (middle) and produces scan image at interface substructure [42].

Abnormal deviations from the expected GPR response can indicate ballast fouling or infiltration of subgrade grains into the upper zones. This approach has successfully captured the invisible mud pumping as well as the fouled ballast [15, 43]. Figure2 presented the scattering envelop analysis at different phase of fouling ballast using GPR application. From scatter analysis in Figure 6 shows there is trapped water pond clearly illustrated in blue color mark on the right phase. Unlike ballasted track, GPR is not suitable to detect mud pumping in subgrade bed under ballastless track as the electromagnetic wave cannot pass and reflect through the track structure which contains several layers of reinforcing steel bars [44,45]. The generation of mud pumping in ballastless track causes contact loss between track structure and subgrade bed. Thus, Huang et al. [46] used the combination of GPR and impact echo (EIM) method to detect mud pumping occurrence at ballastless track as the EIM application had been widely used to detect certain defects inside concrete elements or structures $[47,48,49]$.

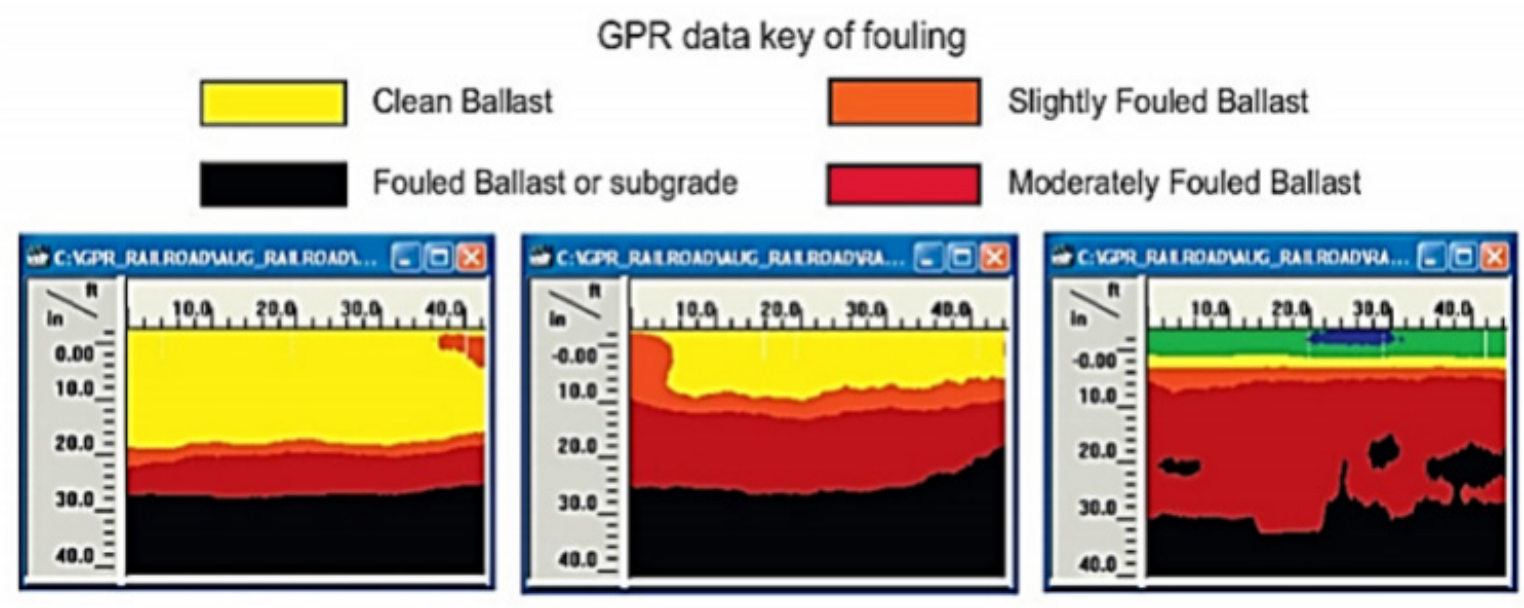

Figure 6. Scattering envelope analysis of increment fouled ballast (left to right) [42] 


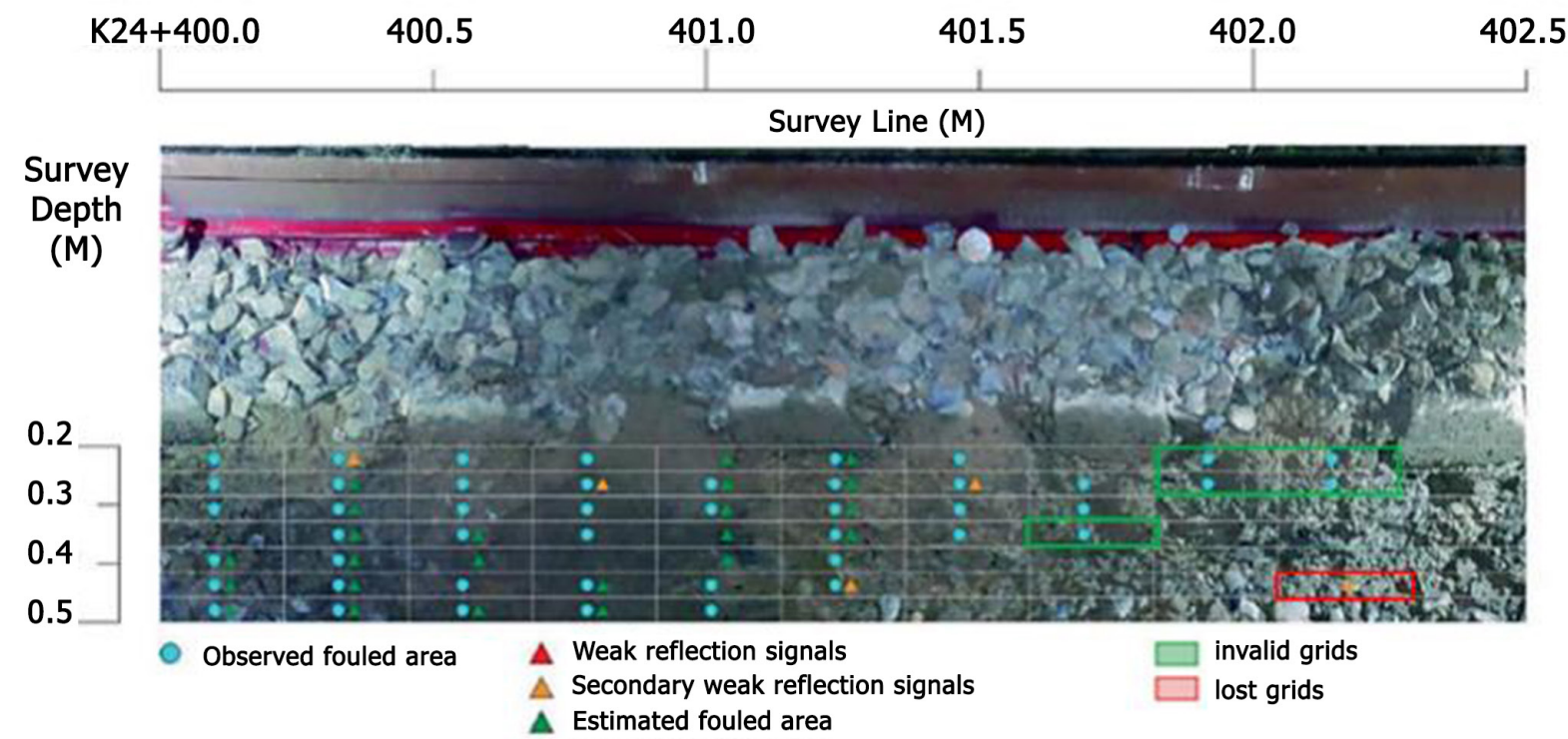

Figure 7. Comparison between observation (excavation) result and interpretation result [41].

In analysis the mud pumping range, the effective GPR signal interpretation method has to be developed in order to avoid misinterpretation data signalized [41]. A study by Kuo [41] had developed reliable signal interpretation method such as characterized grid method and scoring method [50] that achieved $80 \%$ of accuracy rate in assessing mud pumping distribution. Fig. 7 below shows the interpretation analysis when comparing on the excavation result at Taiwan track line. The grid characterization was divided into three categories such as weak reflection signal (red triangle), secondary weak reflection signal (yellow triangle) and estimated fouled area (green triangle) while excavation result presenting the blue circle as observed fouled area. Meanwhile the green grid represents as invalid grid and the red grid defined as lost grid. From the analysis, the study had proved the mapping visualization using GPR is valid as the excavation mapping result well defined which resulting overall precision rate was $82.1 \%$. Therefore, the GPR with additional effective interpretation signal method is highly recommended as reference/guidance for railway maintenance team to assume the range and volume of ballast replacement and at the same time applicable/beneficial in reducing the labor and material cost [41].

The GPR application is beneficial in railway inspections as this method is non-destructive, fast, reliable and cost-effective. The integrated analysis of railway structure helps to define the root cause of the defects and make the rehabilitation work planning more effective and economical. Besides, the development of frequency analysis of GPR signal helps to improve the information on structural parameter such as ballast fouling and pumping. The GPR method is also qualified to be used in identify the subgrade soil degradation by analyzing the frequency parameter [SIL-51].

\subsection{Laboratory Test}

Laboratory testing is used to identify the fundamental parameters of subgrade soils which is known as complicated element to be proved. In the context of subgrade degradation problems, there are two ways to identify those parameters such as creation of mud pumping physical model and analysis mud sample collected from the site.

\subsubsection{Analysis Sample of Mud}

Physical properties investigation of soil normally conducted to obtain and analyse the criteria of mud sample or to identify the exact sources of fine grain. The laboratory test results on the mud sample taken from problematic sites such as the water content, plasticity index and particle size distribution (PSD) can be utilized to evaluate mud pumping induced by subgrade fluidisation. For example, the greater the degree of saturation, the more susceptible soil is to fluidisation [32] and the greater the cohesion of soil, the more resistance to mud pumping. The soil type can be used to classify the sedimentation properties which are prone to mud pumping during flooding as shown in Fig. 6.

Subgrade soil properties play an important role in generating fine particles which contribute to mud pumping activity, while low plasticity and high permeable soils are capable of exaggerating the dissipation of excess pore water pressure that will dislodge fines into the upper coarse layers thus allow the subgrade degradation to take place [42]. Fig. 8 summarized the plasticity index chart which is prone to mud pumping activity of previous researcher and most soil samples are closely to A-line, indicating that soil samples are inorganic clay soil types. Somehow, in cases of mud pumping, the subgrade does not necessarily involve a soft soil consisting of a high 
void ratio and low shear strength because the soil can undergo fluidisation when under repeated loads. However, these soil parameters must be considered with the cyclic loading properties, so advanced physical tests are needed to fully capture the mud pumping mechanism. For example, Alobaidi and Hoare [37] performed a laboratory investigation using a triaxial pumping test and realized that a number of cycles, stress magnitude, saturated subgrade, and loading frequency are considered the fundamental parameters which affect pumping activity.

On the other hand, for visible mud pumping cases the investigation/analysis using laboratory test on micro-characteristic classification of different fine grained of sample from site will allow investigator to figure out the sourced outcome. The accuracy will be doubtful/disputed if the predominant type of fines is not clearly identified, thus unable to explain the subgrade failure thus requires deep excavation for detailed investigation

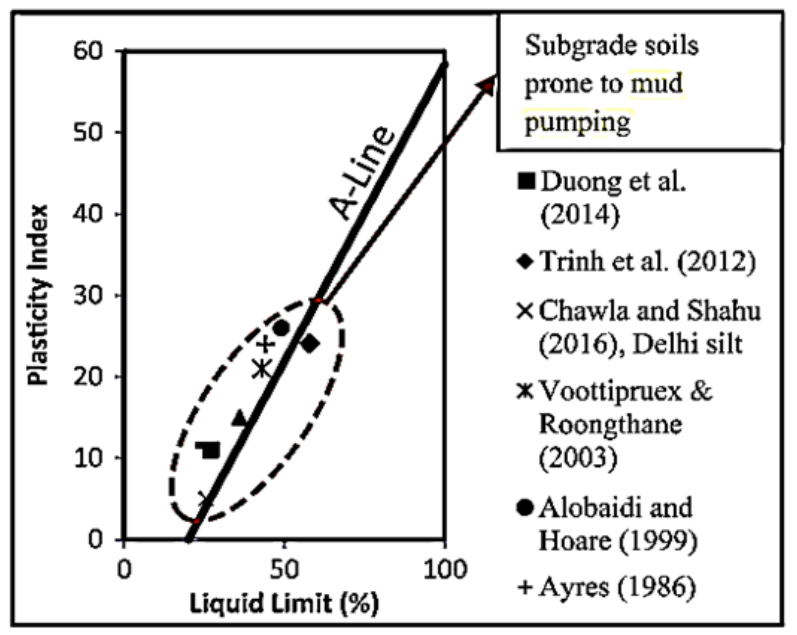

Figure 8. The plasticity index value on severe mud pumping sites [4]

\subsection{Physical Modelling}

Model tests can be individually assessed either ballast degradation, subgrade softening or interaction between ballast-subgrade interaction under cyclic loads $[44,45,46]$. Several model tests have been conducted to determine the subgrade fine migration as the mud pumping mechanism. For example, the similar approach in investigation of pumping of subgrade particle effect in pavement system conducted by Kermani et al. [41] using a one-third- scale Model Mobile Load Simulator (MMLS3), which focuses on the parameters most relevant to pumping of subgrade soil into the subbase layer.

Meanwhile, Duong et al. [26] adopted physical model to study the interlayer creation which is closely related to the migration of fine particles in the conventional railway substructure. The model was used to directly monitor the variations of pore water pressure and volumetric water content, which allowed the migration of fine particles to be investigated. The model designated with $550 \mathrm{~mm}$ Perspex triaxial cell as a compacted subgrade layer consisting of soil mixture (70\% crushed sand and 30\% kaolin clay) and $160 \mathrm{~mm}$ ballast thickness was placed on a top subgrade to present as similar real substructure system (Fig. 9). From the observation they found that the development of pore water pressure in the subsoil was identified as the key factor causing the migration of fine particles thus resulting the interlayer formation, as well as mud pumping.

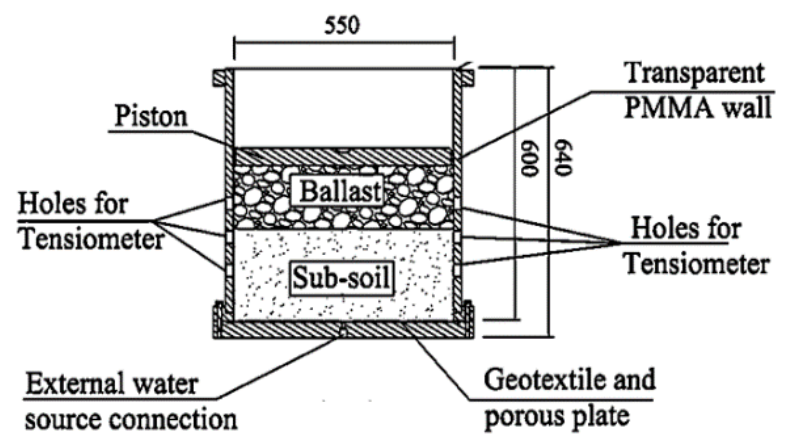

Figure 9. Schematic diagram of physical model component [26]

Fig. 10 presents the pore water pressure value under monotonic and cyclic loading using tensiometer. The cyclic loading process induces the dissipation of pore water pressure as generating the hydraulic exit gradient acting as the main driving force to push the fine subgrade soil into the ballast void. The pore water pressure at all three levels decreased when the monotonic loading was completed. However, the remaining value was higher than zero due to very low hydraulic conductivity of the subsoil affecting the dissipation of pore water pressure.

On the other hand, the sharp increase of pore water pressure under $5 \mathrm{~Hz}$ cyclic loading has weakened the subsoil as the increase in dissipation brings upward the fine particles. The result from this physical model was also consistent with the observation reported by Aw [52] and Indraratna et al. [53] whereby the mud pumping formation was identified in the zone with presence of water, which softens the base layer and allows the migration of the fine particles into the ballast void spaces and intermixing between ballast subgrade layers. Therefore, the assessment using model creation is relevant to the study of the mud pumping phenomenon if the quality of the recorded data showed from the physical model developed worked well and the procedure adopted was appropriate.

Meanwhile, the modelling creation acts as one of alternative method to identify numerous parameters especially on complex indicator in soil degradation rather than relying on theoretical assumption. There are no worries/uncertainties on the costing and time valuable as the model can be designed depend on the parameter needed or objective required. In addition, this method is suitable for prediction purposed in time using simulation 
analysis to identify the correlation between field data and laboratory test. Therefore, for a more reliable assessment in subgrade degradation, the combination of the assessment is a must for better insight/explore on mud pumping problem and the modelling helps to support other defined soil parameter especially relating to the movement of pumping fines during loading phase.

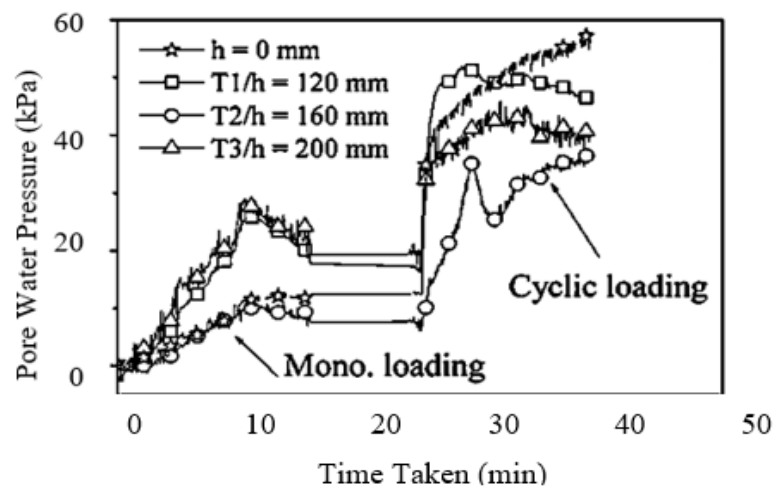

Figure 10. Pore water pressure from tensiometer [26]

\section{Conclusions}

The typical assessment is chosen depending on the seriousness of the mud pumping that appears on site by using visual observations. Ground penetration radar (GPR) technique has shown significant success in identifying and analyzing mud pumping in the field as required interpretation method of signal analysis to enhance the accurateness of data. Assessment technique on mud pumping occurrence using GPR has been practiced in the field, but detail guideline to assess mud pumping with minimal time and cost has not been addressed properly. The previous researchers mainly focus using GPR application in identifying fouling ballast compared to the pumping of subgrade fine. GPR is a valuable investigative tool that can be used to determine the ballast fouling index (FI). Thus, excavation can be used for data comparing with the GPR for better imaging analysis. Laboratory and modelling tests reliable in evaluating the subgrade performance as the mud samples can be collected for detailed fraction analysis to identify the source of mud fines while the modelling test is more suitable for soil parameter prediction. Based on the comparison of various methods, geological radar detection is an effective measure to identify and recognize the type of railway subgrade mud pumping. Applicability of various assessments for mud pumping that were systematically reviewed will be useful reference for railway subgrade mud pumping investigation.

\section{Acknowledgments}

The authors would like to express sincere gratitude to Ministry of Higher Education Malaysia (MOHE) for financial support of this research work under the FRGS scheme (600-IRMI/FRGS 5/3 (302/2019). The appreciation also goes to all parties that have supported and involved in this research especially to Universiti Teknologi MARA, Pulau Pinang for the facilities.

\section{REFERENCES}

[1] Selig, E. T., and Waters, J. M., Subgrade Behavior: Track Geotechnology and Substructure Management, 10.1-10.43, https://doi.org/10.1680/tgasm.20139.0010, 1994.

[2] Voottipruex, P., \& Roongthanee, J., Prevention of Mud Pumping in Railway Embankment, The Journal of KMITNB, 13(1), 20-25, 2003.

[3] Kuo, C., Hsu, C., Wu, C., Liu, P. and Chen, D., Study on the piping path and mechanism of mud pumping in railway subgrade, In Proceedings of the 19th International Conference on Soil Mechanics and Geotechnical Engineering (ISSMGE), Seoul, pp. 1051-1054, 2017.

[4] Nguyen, T. T., Indraratna, B., and Phan, N. M., Mud Pumping Under Railtracks: Mechanisms, Assessments and Assessments. Australian Geomechanics Journal, Volume 54, Issue 4, Pages 59-80, 2019.

[5] Hayashi, S. and Shahu, J.T., Mud pumping problem in tunnels on erosive soil deposits, Géotechnique, 50(4): 393$77,2000$.

[6] Liu, D., Fu, H., Zhu, X., Liu, Y. and Rao, J., Study on the remediation of mud pumping, Applied Mechanics and Materials, 275-277: 1560-1563, 2013.

[7] Muramoto, K., Sekine, E. and Nakamura, T., Roadbed degradation mechanism under ballastless track and its countermeasures, 2006.

[8] Muramoto, K. and Nakamura, T., Development of the countermeasure against roadbed degradation under ballastless tracks for existing lines, In Proceedings of the 9th World Congress on Railway Research, Lille, pp. 1- 10, 2011.

[9] Chawla, S., \& Shahu, J. T., Reinforcement and mud-pumping benefits of geosynthetics in railway tracks: Model tests, Geotextiles and Geomembranes, 44(3), 366380, https://doi.org/10.1016/j.geotexmem.2016.01.005, 2016

[10] Wang, Y., Kong, L.W., and Wang, Y. L., Mechanism and Control of Subgrade Mud Pumping Under the Cyclic Load of Train. International Conference on Mechanics and Civil Engineering (ICMCE, (January), https://doi.org/10.2991/ic mce-14.2014.63, 2014.

[11] Selig, E.T. and Waters, J.M., Track geotechnology and sustructure management, Thomas Telford, London. p.464, 1994.

[12] Feldman, F. and Nissen, D., Alternative testing method for the measurement of ballast fouling, In Proceedings of the RTSA conference on railway engineering, Wollongong, NSW. pp. 101-109, 2002. 
[13] Sussmann, T.R., Ruel, M. and Chrismer, S.M., Source of ballast fouling and influence consideration for condition assessment criteria, Transportation Research Record, 2289: 87-94, 2012.

[14] McDowell, G.R., Lim, W.L., Collop, A.C., Armitage, R. and Thom, N.H., Laboratory simulation of train loading and tamping on ballast. Proceedings of the Institution of Civil Engineers Transport, 158(2): 89-95, doi:10.1680/tran.2005 $.158 .2 .89,2005$.

[15] Lenart, S., Bizjak, K.F., Noren-Cosgriff, K., Kaynia, A.M., Kramar, M., Vajdić, M., Chen, K. and Clarke, J., Guidelines on the use of novel construction and maintenance techniques within the operational railway environment, DESTination RAIL - Decision Support Tool for Rail Infrastructure Managers, 2018.

[16] Ionescu, D., Ballast degradation and measurement of ballast fouling, In Proceedings of the 7th Railway Engineering Conference, July, London. pp. 169-180, 2004.

[17] Tutumluer, E., Dombrow, W. and Huang, H., Laboratory characterization of coal dust fouled ballast behavior, In AREMA, 2008

[18] Johan, S. F. S., Enhanced Shear Resistance of Rail Tracks With Ballast-Rubber Composites: A Laboratory Work, UTHM, 2015.

[19] Cho, Y., Park, D.S., Lee, J.Y., Jung, W.S., Kim, H.M. and Lim, J.L., Dry Cleaning of Railroad Ballast Gravels by Blasting with Thermossetting Plastic Resin Powder, Korea Railroad Research Inst. Uiwang Korea, 2008.

[20] Ayres DJ, Geotextiles or Geomembranes in track, British Railways experience. Geotext Geomembr, 3:129-142, 1986.

[21] Singh, M., Indraratna, B., \& Rujikiatkamjorn, C., Use of geosynthetics in mitigating the effects of mud pumping: In Lecture Notes in Civil Engineering Vol.29, pp.609-618, https://doi.org/10.1007/978-981-13-6713-7_48, 2019.

[22] Takatoshi, I., Measure for the Stabilization of Railway Earth Structure Japan Railway Technical Service, Tokyo, Japan, 1997.

[23] Hudson, A., Watson, G., Le Pen, L. and Powrie, W. Remediation of Mud Pumping on a Ballasted Railway Track. Procedia Engineering, 143: 1043-1050, doi: https://doi.org/10.1016/j.proeng.2016.06.103, 2016.

[24] Sussmann, T. R., Thompson, H. B., Stark, T. D., Wilk, S. T., \& Ho, C. L., Use of seismic surface wave testing to assess track substructure condition. Construction and Building Materials, 155, 1250-1255. https://doi.org/10.1016/j.conbu ildmat.2017.02.077, 2017.

[25] Yu, S., Leng, W. M., Teng, J. D., Nie, R. S., \& Qi, Y., Analysis of subgrade soil mud pumping model. Electronic Journal of Geotechnical Engineering, 21(24), 7667-7678, 2016.

[26] Duong, T. V., Cui, Y. J., Tang, A. M., Dupla, J. C., Canou, J., Calon, N., De Laure, E., Physical model for studying the migration of fine particles in the railway substructure. Geotechnical Testing Journal, 37(5). https://doi.org/10.152 0/GTJ20130145, 2014.

[27] Cai, X., Cai, X., Liu, K., \& Wang, H., Study on Mud
Pumping Mechanism of Subgrade Surface Layer in Slab Ballastless Track Zone, Sensors \& Transducers by IFSA Publishing, 186(3), 154-160, 2015.

[28] Wong, R.C.K., Thomson, P.R., Choi, E.S.C., In situ pore pressure responses of native peat and soil under train load: a case study, J. Geotech. Geoenviron. 132 (10), 1360-1369, 2006.

[29] Kettil, P., Lenhof, B., Runesson, K., Wiberg, N.E., Coupled simulation ofwave propagation and water flow in soil induced by high-speed train, Int. J. Numer. Anal. Methods Geomech. 33, 1311-1319, 2008.

[30] Li, S., Lai, Y., Zhang, S., Yang, Y., Yu, W., Dynamic responses of Qinghai-Tibet railway embankment subjected to train loading in different seasons, Soil Dyn. Earthq. Eng. $32,1-14,2012$.

[31] Li, D., 25 years of heavy axle load railway subgrade research at the Facility for Accelerated Service Testing (FAST). Transportation Geotechnics, 17: 51-60, doi: https://doi.org/10.1016/j.trgeo.2018.09.003, 2018.

[32] Duong, T.V., Cui, Y.-J., Tang, A.M., Dupla, J.-C., Canou, J., Calon, N. and Robinet, A., Investigating the mud pumping and interlayer creation phenomena in railway sub structure. Engineering Geology, 171: 45-58. https://doi.org/10.1016/j .enggeo.2013.12.016, 2013.

[33] Trinh, V. N., Tang, A. M., Cui, Y. J., Dupla, J. C., Canou, J., Calon, N., Lambert, L., Robinet, A., and Schoen, O., Mechanical Characterisation of the Fouled Ballast in Ancient Railway Track Sub-Structure by Large-Scale Triaxial Tests, Soils Found, Vol. 52, No. 3, pp. 511-523, 2012.

[34] Kuo, C., Hsu, C., Wu, C., and Chen, D., Study on the mechanism and inspection method of railway pumping, The 10th International Conference on Bearing Capacity of Roads, Railways and Airfields (BCRRA2017), Athens, Greece, 2017.

[35] Read, D., Hyslip, J. and McDaniel, R., Heavy axle load revenue service mud-fouled ballast investigation, In Tech Report. Federal Railroad Administration, US. Department of Transportation, 2011.

[36] Roghani, A., A quantitative evaluation of the impact of soft subgrades on railway track structure. Department of Civil and Environmental Engineering, Doctoral Thesis, 2017.

[37] Alobaidi, I. and Hoare, D., Factors Affecting the Pumping of Fines at the Subgrade-Subbase Interface of Highway Pavements: A Laboratory Study, Geosynthetics International, Vol.1, No.2, pp. 221-259, 1994.

[38] Henry, K. S., Cole, D. M., \& Durell, G. D., Mixing in an Aggregate/Fine-Grained Soil System Subjected to Cyclic Loading with a Geotextile Separator, In Sound Geotechnical Research, pp. 306-317, 2013.

[39] Kermani, B., Stoffels, S. M., \& Xiao, M., Assessment of Geotextile Effectiveness in Decreasing Subgrade Pumping and Increasing Service Life in Rigid Pavements Using Scaled Model Mobile Load Simulator. Geotechnical, 357367, https://doi.org/10.1061/9780784482124.037, 2019

[40] Li, D., \& Selig, E. T., Evaluation of railway subgrade problems. Transportation Research Record, (1489), 17-25, 
1995.

[41] Kuo, C., Ground-penetrating radar to investigate mud pumping distribution along a railway line. Construction and Building Materials, 290, 123104.

https://doi.org/10.1016/j.conbuildmat.2021.123104, 2021.

[42] Bold, R. De., O'Connor, G., Morrissey, J. P., and Forde, M. C., Benchmarking large scale GPR experiments on railway ballast, Construction Building Materials, Elsevier 31-42, 2015.

[43] Kuo, C., Hsu, C., Chen, Y., Wu, C., Wang, H., Chen, D. and Lin, Y., Using ground penetration radar to promote the investigating efficiency in mud pumping disaster of railways, In Proceedings of the Engineering and Technology Innovation, 2016.

[44] Daniels, D. J., "Ground penetrating radar," in Encyclopedia of RF and Microwave Engineering, Wiley, Hoboken, NJ, USA, 2005.

[45] Soldovieri, F., Persico, R., Utsi, E., and Utsi, V., The application of inverse scattering techniques with ground penetrating radar to the problem of rebar location in concrete, NDT\& E International, vol. 39, no. 7, pp. 602-607, 2006.

[46] Huang, J., Su, Q., Liu, T., and Wang, W., Behavior and Control of the Ballastless Track-Subgrade Vibration Induced by High-Speed Trains Moving on the Subgrade
Bed with Mud Pumping. 2019.

[47] Zhang, J., Yan, W., and Cui, D., "Concrete Condition Assessment using Impact-Echo Method and Extreme Learning Machines, Sensors, vol. 16, no. 4, p. 447, 2016.

[48] Kaewunruen, S., and Remennikov, A. M., Field trials for dynamic characteristics of railway track and its components using impact excitation technique, NDT \& E International, vol. 40, no. 7, pp. 510-519, 2007.

[49] Hsieh, C. T., and Lin, Y., Detecting debonding flaws at the epoxy-concrete interfaces in near-surface mounted CFRP strengthening beams using the impact-echo method, NDT\& E International, vol. 83, pp. 1-13, 2016.

[50] Hsu, C. H., Using characterize grids resolving method for GPR on investigating railway mud pumping, Minghsin University of Science and Technology, Master's thesis, 2017.

[51] Silvast, M., Levomäki, A. and Nurmikolu, J. N., NDT Techniques in Railway Structure Analysis, 2015.

[52] Aw, E.S., Low cost monitoring system to diagnose problematic rail bed: case study at a mud pumping site, Doctor of Philosophy, Thesis, Massatchusetts Institute of Technology, 2007.

[53] Indraratna, B., W. Salim, and C. Rujikiatkamjorn, Advanced rail geotechnology, ballasted track. Boca Raton, FL: CRC Press, 2011. 